\title{
Multilingualism in Stroke Patients: A Personal Account
}

\author{
Jürg R. Schwyter ${ }^{1,2}$ \\ ${ }^{1}$ Department of English, University of Lausanne, Lausanne, Switzerland \\ ${ }^{2}$ Robinson College, Cambridge, UK \\ Correspondence: Jürg R. Schwyter, Department of English, University of Lausanne, CH-1015 Lausanne-Dorigny, \\ Switzerland. Tel: 41-21-692-2989. E-mail: JurgRainer.Schwyter@unil.ch
}

Received: March 14, 2013 Accepted: April 17, 2013 Online Published: May 17, 2013

doi:10.5539/ijel.v3n3p15 URL: http://dx.doi.org/10.5539/ijel.v3n3p15

\begin{abstract}
Multilingualism is a highly complex phenomenon and even more so in the recovery pattern of stroke patients. This papers addresses the following factors with respect to multilingual stroke patients: the age of acquisition of languages, the place of lesion, the language proficiency at the time of the stroke and its recovery during post-stroke training, the speaker's emotional involvement with the languages and the relative distance between languages. The age of acquisition of languages appears to be of lower importance, and multilingual language recovery of patients with Broca's area stroke is more complex than that of bilingual patients. Importantly, the languages used prior to the lesion, and the language used during language therapy are highly relevant. Closely linked is the emotional involvement with the various languages in a multilingual person; the deeper the integrative motivation, the more successful the recovery. From a linguistic point of view, the relative distance between languages appears to be of lower importance despite some indications put forward by neurolinguists and clinicians. Quantifiable and measurable parameters, such as the age of acquisition and the place of lesion, have been studied much more frequently than comparatively imprecise ones on emotional involvement and language proficiency/competence at the time of a stroke. But it is exactly the latter parameters that most progress can and should be made on in the future.
\end{abstract}

Keywords: multilingualism, stroke patients, aphasia, language recovery

\section{Introduction}

Multilingualism is not easy to define, and a variety of statements about the exact meaning of the term can be found in the literature (see e.g., Bahtia \& Ritchie, 2004). Broadly speaking, a multilingual person is somebody who can communicate in more than two languages, which of course raises the question of the meaning of "communicate" and "language". (Note 1)

The ability to "communicate" in more than two languages involves learning, maintaining and using these languages either on more or less equal terms (a balanced multilingual), or with one language dominant but with the others strong enough for the person to function in them (L1 dominance).

The question of what is a "language" is even trickier. There is the criterion of mutual intelligibility: two varieties that are mutually intelligible form a single language (e.g., Flemish and Dutch), while two varieties that are not are considered to be two separate languages (e.g., French and German). A language can be conceived of as an autonomous variety (e.g., Standard German) along with all its dependent heteronomous varieties (e.g., Bavarian, Plattdeutsch, etc.). The autonomous/heteronomous distinction is, of course, linked to political and historical realities. Should Luxembourgish and Swiss German, for example, be seen as varieties of German or as independent languages? It is clear that we are dealing with both fuzzy and discrete language boundaries.

The second half of the 20th century, and the 21 st century in particular, have seen an explosion in studies of multilingual patients who have experienced brain damage or strokes, and the recovery of their language abilities (for an overview, see for example Gitterman, Goral \& Obler, 2012, and Obler \& Gjerlow, 1999).

How can a stroke patient who spoke several languages, either autonomous or heteronomous varieties, recover and use these languages as well, or nearly as well as, before the stroke? And how can they overcome aphasia in several - or all - of these languages? Does the stroke patient have access to one language system or multiple language systems in the brain? And how can one distinguish between all of these languages in the brain - for 
example, are there one or more language centres for each language in the brain? Research has shown that during bilingual language recovery, about $45 \%$ of aphasia victims experience parallel recovery, that is, the two languages recover to the same level at the same rate; $25 \%$ and $20 \%$ respectively have a better command of their L1 or L2, and the remaining $10 \%$ either switch languages within a sentence or alternate languages between sentences (figure 1).

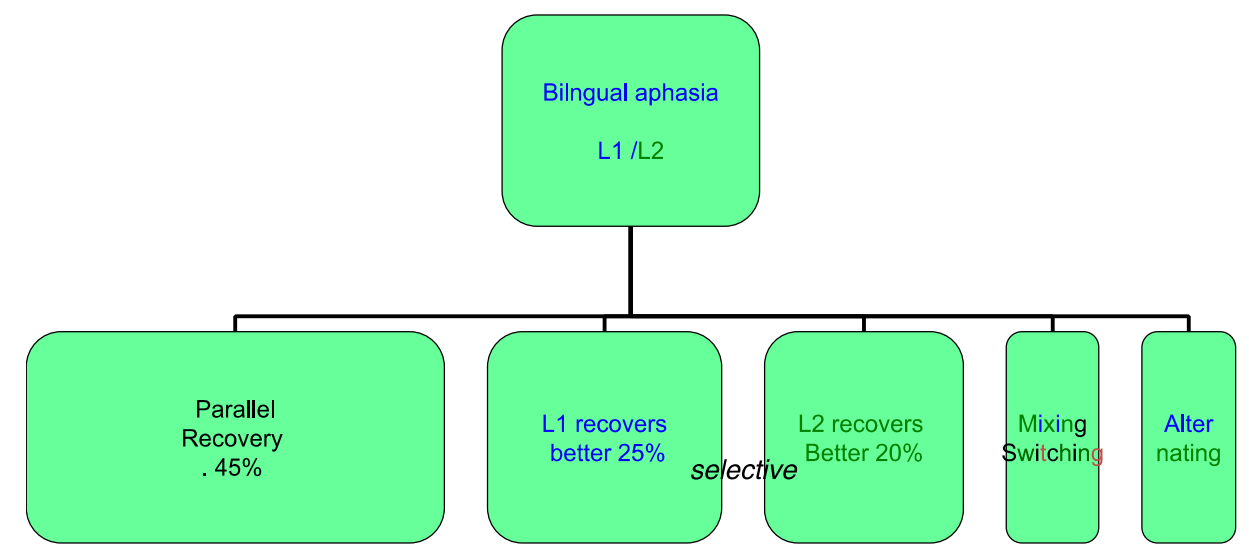

Figure 1. Bilingual language recovery after a stroke (Fabbro et al., 2001, quoted by Annoni, 2011)

Description: The bilingual recovery patterns of languages after a stroke is complex though most patients undergo parallel recovery.

To address these issues surrounding multilingual stroke patients, I will discuss in turn the age of acquisition of the L2, L3 and L4 etc.; the place of lesion; language proficiency at the time of the stroke and its recovery during post-stroke training; the speaker's emotional involvement with the languages; and the relative distance between languages.

In the discussions below, I will draw on my personal experience, as I have had a stroke in February 2009. I used to speak and understand five languages (in sequence of acquisition: Swiss German, Standard German, French, English, and Italian), and at the time of writing in early 2013, I have recovered $2 \frac{1}{2}$ of them. Swiss German and English are fully restored, and I am still undergoing speech therapy for my French. So far, however, there has been very little or no recovery of my active command of Standard German (the passive mode, however, is always "there", and I can read, understand the TV, and so on), or my Italian. This raises a number of interesting questions, some of which I will discuss below.

\section{Age of Acquisition}

Generally speaking, the critical period for language acquisition is said to be somewhere in late childhood or early puberty. Afterwards, learning languages may become more difficult as connections between brain cells (brain plasticity) are lost to a considerable extent. However, this may be only partly true, as brain cells continue to make connections with each other, albeit at a somewhat slower speed; the ability to learn new things, including languages, is by no means lost (Schwyter, 2011).

For people who speak more than one language or dialect, recovery processes after a stroke are complex. Some multilinguals can recover all their languages or dialects, some just a few, and some struggle even with their L1. This led early neurolinguists to postulate that there are a number of "language centres" in the brain, and that for each language the comprehension centre (Wernicke's area) and production centre (Broca's area) is different. For a trilingual person, then, this would give six different cerebral centres.

It was only in the early 20th century that Mieczyslaw Minkowski, a Swiss neurologist, questioned the notion of language centres and proposed that there is a common language area (Ijalba, Obler \& Chengappa, 2004). His study suggested that languages which are learned later are superimposed in the brain on languages learned first, and that stroke and aphasia damage results in greater impairment of later-learned languages. The age of language acquisition, therefore, needs to be taken into account (Ijalba, Obler \& Chengappa, 2004).

In multilingual Switzerland, the language acquisition pattern for the German-speaking areas in the 1970s when I 
went through the education system would have looked something like table 1.

Table 1. Language acquisition in German-speaking Switzerland in the 1970s

\begin{tabular}{lll}
\hline Sequential order & Language & Age of acquisition \\
\hline L1 (mother tongue) & Swiss German & birth \\
L2 & Standard German & age 7 \\
L3 & French & age 13 \\
L4 & English & age 15 \\
L5 & Italian & age 17
\end{tabular}

As shown in table 1 , the sequential order of language acquisition indicates the acquisition of Standard German to begin in primary school, followed by three additional languages in secondary school.

According to Minkowski, all of these languages should have a common or shared neural representation, and recovery after a stroke should also be similar among later-learned languages. However, we know that this is not so. Albert \& Obler (Ijalba, Obler \& Chengappa, 2004) stated that, in multilingual aphasia, all languages recover proportionately to their pre-stroke proficiency; and if they do not, the language most frequently used at the time of the patient's lesion is the one recovered first.

Language recovery in a multilingual patient is neither easy nor straight-forward. Paradis (Ijalba, Obler \& Chengappa, 2004) has found that parallel recovery, as discussed by Albert \& Obler, and antagonistic recovery (progress in one language, regression in the others) are the most frequent patterns. For the latter, antagonistic recovery, Green (2009) has found that "a small difference in the rates of recovery, reflecting perhaps different degrees of damage to the [linguistic] system, will be sufficient to induce different end-states in the course of language use. An initially less dominant language schema becomes more and more dominant" (emphasis mine). This ties in nicely with Annoni's (2011) diagram (figure 1 above), where these two scenarios, parallel and antagonistic recovery, account for up $90 \%$ of bilingual language recovery after a stroke.

In recent years, the importance of the age of acquisition has gained currency again. For example, it has been found that earlier-acquired languages are more left-lateralized and later-acquired languages are more bilaterally represented; however, no data was found that statistically linked the pattern of recovery from aphasia to the age of acquisition of the various languages in a multilingual speaker (Ijalba, Obler \& Chengappa, 2004).

So far, I have recovered my mother tongue, Swiss German, almost perfectly, but can no longer speak Italian, which I studied for two years starting at the age of 17. This pattern ties in nicely with the parallel recovery scenario discussed by Albert and Obler. Even my recovery of English fits their expectations, since I had high proficiency in it and used it very frequently for my work. But my failure to recover French is more difficult to explain, and even more inexplicable is my inability to recover a command of Standard German, which I studied from the age of 7, definitely early enough for left-lateralisation to occur. We could imagine that this is a case of antagonistic recovery - that is, I have almost entirely lost my Standard German, while regaining my Swiss German and English. But, there maybe something else at work in my language repertoire, such as the place of lesion where the stroke occurred, my various language proficiencies at the time of the stroke, their recovery during post-stroke training, and even my emotional involvement with these languages.

\section{Place of Lesion}

The place of lesion in a stroke patient is relatively easy to determine. A brain scan (e.g., magnetic resonance imaging, MRI) will tell whether it is a front (anterior), front-back (anterior-posterior), or back (posterior) lesion. In a paper published in 2011, and dealing only with bilingualism, researchers found that patients with anterior lesions performed better in L1 syntactic tasks than in their L2, and that there was also a dissociation of L1 and L2, that is the two languages were not connected in their grammar and morphology (Tschirren et al., 2011). However, for anterior-posterior and posterior lesions there was a markedly better performance in L2 syntactic tasks, that is, in L2 grammar and morphology. Since this was a pilot study involving only 12 patients, the results are hardly conclusive. But we can still postulate the following tendency: in Broca's area strokes, i.e., the frontal lobe of the left cerebral hemisphere (figure 2), we have a clear dissociation of languages, with better L1 performance. 
Broca's area is one of the principal speech motor areas. Injuries in this region will affect speech output greatly, for example causing severe phoneme confusion (from an English perspective, $\theta$ versus $t, \int$ versus $\mathrm{s}, \mathrm{r}$ versus 1 , etc.), faulty sentence structure and telegraphic style (e.g., no function words, no is, it, or have), and a total lack of prosodic features such as stress, rhythm and intonation (for example, no stress in three and four syllable words such as aca'demic and post'graduate). A markedly better performance in the L1 - vis-à-vis the L2, L3, etc. - is therefore expected in a Broca's area trauma, as there is clear disassociation of the L1 from the other languages in the repertoire.

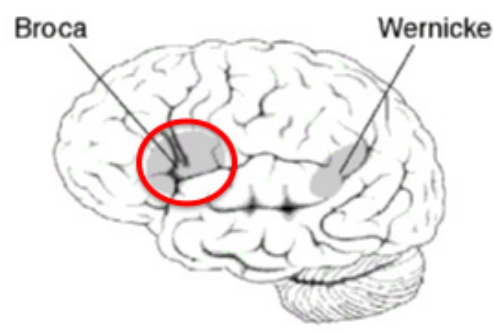

Figure 2. Broca's area (National Institute of Health. October 2008. NIH Pub. No. 97-4257 http://www.nidcd.nih.gov/health/voice/pages/aphasia.aspx)

Description: Broca's area is the principal motor speech centre in the brain. A lesion in that area causes aphasia.

Having suffered a Broca's area stroke, I was initially totally mute (together with having comprehension difficulties - this is referred to as global aphasia). I experienced all or most of the Broca's aphasia difficulties with speech articulation, but thanks to intensive speech therapy in the weeks after my stroke, I soon recovered my L1 (Swiss German). But what about my other languages, first and foremost Standard German? Are they dissociated from my L1 and, if so, could they be recovered as well?

With intensive speech therapy conducted by a German-English bilingual therapist, I also recovered my English. Standard German, however, is now extremely difficult for me: I speak it more slowly and with a very strong Swiss German accent (which I didn't before the stroke), and I also make the odd mistake (for example, Swiss German does not have a genitive and expresses those relationships with the dative, something I now tend to do in Standard German as well). Sociolinguistically, Swiss German may be a variety heteronomous to Standard German, but in my brain they are separate.

\section{Language Proficiency at the Time of the Stroke and Its Evolution during Post-Stroke Training}

As discussed above, highly varied patterns of recovery are to be expected in multilingual patients. One possible influence, as just noted, might be the proficiency and frequency of use of each language before the stroke. Also, the question has still not been answered as to whether, during rehabilitation, there is transfer from the language in which the patient undergoes speech therapy to the language(s) not involved in speech therapy. Usually, there is more recovery in the former than the latter, unless the patient is a fully balanced bilingual speaker (Meinzer, Obleser, Flaisch, Eulitz, \& Rockstroh, 2007).

The case of a 35-year-old German-French bilingual individual who suffered a stroke at the age of 32 (taken from Meinzer et al., 2007) is very revealing. He is highly educated (he has a Ph.D.) and is the son of a German father and a French mother. At the age of 3, the family moved from France to Germany. He used both languages on a daily basis - including professionally, since he was employed at an international law firm - but it was French he used at home and German in everyday life. Later he also acquired English and Italian.

His stroke at the age of 32 caused severe Broca's aphasia. In the acute phase, the patient's language disorder was diagnosed as global aphasia (with both production and comprehension difficulties), which began to improve only after 3 months. His long-term rehabilitation had been provided exclusively in German and amounted to 3 hours per week. The patient's relatives and friends also only spoke German with him, on the advice of the speech and language therapist.

His therapeutic naming-task training was conducted only in German. He performed better in German (in which he received speech therapy) than in French (no speech therapy) throughout; his French system remained "dormant", showing no transfer effect. After further German language training, his performance on the German naming task was markedly improved while his French performance remained unchanged. In short, this 
German-French bilingual patient is a striking example of the effects of language use together with therapy-related language recovery.

While there are many clinical assumptions about which language will show least impairment or recover the best, such ideas may be based on clinical lore and are often contradictory. A review of the literature finds that the outcome of brain injury may be influenced by other factors, including the method of language acquisition, the age of acquisition, and, above all, the use of a language or languages and training-related recovery. As stated above (Ijalba, Obler \& Chengappa, 2004): if languages do not recover parallel to pre-stroke levels, which is the case with this French-German bilingual, the language most frequently used at the time of the patient's lesion and during speech therapy is the one first recovered, and the others follow (or don't follow!) suit.

In comparison to the case study above, I used to be Professor of English linguistics at the University of Lausanne, Switzerland prior to my stroke at age 44. I had studied at the University of Pennsylvania, where I received my BA, and at Cambridge University, where I obtained a Ph.D. Thereafter, I was a junior research fellow in Britain, and a teaching and research assistant in Germany. It is easy to see that English was by far the strongest non-native language I had command of before the stroke. I wrote, read, conversed and joked in English about $75 \%-80 \%$ of the time (see table 2 ).

Table 2. Language command at the time of stroke and after (Basic User: A1 and A2; Independent User: B1 and B2; Proficient User: $\mathrm{C} 1$ and $\mathrm{C} 2$ )

\begin{tabular}{lll}
\hline Language & Before stroke & After stroke \\
\hline Swiss German & native & near native (C2) \\
Standard German & native & moderate (A2) \\
French & good (B2) & moderate (A2) \\
English & near native (C2) & near native (C1) \\
Italian & moderate (A2) & non-existent
\end{tabular}

As shown in table 2, my recovery pattern, that of a multilingual stroke patient, is complex and highly idiosyncratic.

The remaining $20 \%-25 \%$ of my language use was equally distributed between Swiss German (telephone calls with my family), French (administrative matters in the university) and Standard German (with my partner, who is German); Italian is now entirely absent from my life, except for reading the odd scientific article. It is easy to understand my varied recovery levels of Swiss German, English and French in the light of my language proficiency in these languages before the stroke and speech training-related exercises thereafter, but the almost complete lack of recovery of Standard German is still not very well explained. Why is it that this language just "isn't in my head" any more? Why is it that my active use of this language has basically vanished?

\section{Emotional Involvement with Languages}

While the place of lesion is easy to locate, the emotional involvement with a language is difficult to capture and quantify. It is perhaps this imprecision that has prevented a useful neurological analysis of the emotional involvement with a language in recovering stroke victims.

Broadly speaking, in language learning one can distinguish between instrumental motivation and integrative motivation. Instrumental motivation is driven by the need to learn a language, for example, to get ahead in life or as a job requirement, while integrative motivation is led by the desire to learn a language, for example, to pursue cultural interests or because one wants to live in the country where the language is spoken. In the short term, one can learn a language very well through instrumental motivation, particularly if one is highly motivated; in the longer term, however, it is integrative motivation that carries one further, as this stays very high (Archibald, 1996). Of course, there are other studies that discuss a speaker's "involvement with languages" and the different attitudes of users towards a language (see e.g., Daneš, 2002), but it is this distinction - instrumental versus integrative motivation - that has allowed sociologists and linguists to study a large population of language learners and the relevant sub-groups therein.

Unfortunately, this approach is too imprecise for neurological purposes, where everything aims to be "precise" and "quantifiable". Sociological and linguistic studies, by contrast, give options, possibilities, and more of a 
balanced interpretation. These two approaches remain somewhat incompatible, in my opinion. Nevertheless, the difference between instrumental motivation and integrative motivation is a useful and important one.

While Swiss German is my mother tongue (the language of my childhood, dreams, etc.) and is naturally associated with a deep emotional involvement, my involvement with English draws upon a very strong integrative motivation; it is the language of my profession and passions. There are speakers of English English and American English on both sides of my family, I studied in England and America, and my professional language, a profession which I love, is English.

In contrast, my other languages - Standard German, French and Italian - were learnt at school purely instrumentally. Standard German is interesting because, although I learnt it at school starting at a very early age (7), it was never more than a means to an end; there was no emotional involvement whatsoever (or even a negative one, because Standard German is perceived as a "foreign" or even "alien" language in Switzerland). A somewhat similar situation holds for Italian and French: the former I would hardly use, except for reading the odd article; the latter I had to brush up before my stroke (but only then) to deal with the university administration, which is not an altogether positive emotional involvement either.

I firmly believe that it is my integrative emotional involvement with English that accounts for this language coming back to me with relative ease and to a high degree after my stroke.

\section{Relative Distance between Languages}

Some theoretical linguists consider the relative distance between languages as quite immaterial - there is, after all, no uniform and generally accepted approach to quantify the linguistic difference or similarity between languages (Crowly \& Bowern, 2009; Renfrew, McMahon \& Trask, 2000). However, it is often argued by neurolinguists and clinicians that proximity between languages aids the recovery of languages not directly targeted in speech therapies through therapeutic transfer, in that "therapy in one language would influence another language at the level of the underlying structures that are common to all languages" (Mali \& Goral, 2004). Recent computational work has led to promising text-based approaches that allow an assessment of the relative distance between languages. One method charts the distances between words with the same meaning; a study was carried out investigating the "Bodleian Oath", which can be taken in more than 30 languages (Rivers $\&$ Golonka, 2009). (Note 2) The measure of a language's difficulty and learnability, however, is relative; clearly, the linguistic distance between languages cannot be measured or quantified so easily. It must also be said that the perceived distance between languages - for example, through a learner's previous, albeit superficial knowledge is not necessarily the same as the actual distance between those languages (Rivers \& Golonka, 2009).

In a simplified manner, English, German and other Germanic languages are members of Proto-Germanic, a sub-family of Proto-Indo-European, and Italian and French are members of the Latin sub-family (Finegan, 1998). Within the Germanic languages, Modern English and Standard German are relatively distant from each other (Lass, 1987). But, Swiss German is very close to Standard German. Quintessentially then, Swiss German/Standard German and French/Italian are related, but not very closely. Nonetheless, they have quite a lot of typological similarities and a certain amount of shared pan-European lexis. The hypothesis thus is that a learner will be stronger in, say, English if the language (sub-)family he or she speaks is (closely) related to English; but other linguistic factors, such as typological features (grammatical gender differences, case system, etc.) and lexis will have more or less significant effects on the performance in English.

In conclusion, one has to say that relative language distance cannot be quantified decisively enough so as to allow firm pedagogical implications or conclusions to be drawn (Elder \& Davies, 1998). The same is true for the effects on multilingual stroke victims with aphasia: there can be no watertight claim that languages from a distant genetic (sub-)family will have a worse recovery level than those with a proximal genetic relationship, even if (say) grammatical or phonological similarities have a marginal influence on the recovery rate.

While relative distance between languages can help explain why, as a Swiss German mother-tongue speaker, I am experiencing a poor recovery of French and total failure to recover Italian, it cannot account for the difficulties I have with Standard German, which I seem to be unable to switch into an active mode.

\section{Conclusion}

Multilingualism is not easy to define, in particular what it means to communicate in all languages, either autonomous or heteronomous, on equal or near-equal terms. Here studies on multilingual stroke patients may be helpful. These studies offer additional insights into the nature of multilingualism at large by highlighting the relative importance of age of acquisition, the brain architecture, proficiency levels, emotional involvement and the relative distance between languages. 
Emotional involvement, current language proficiency, and language practice appear to be more relevant in multilingual competency than for example, the age of acquisition and certain physiological aspects. I have discussed various features in the recovery of multilingualism in stroke patients as they highlight contributing factors of multilingual proficiency.

With regard to the age of acquisition, broadly speaking, the majority of patients perform better in their earliest learnt languages than in their later ones. And we have also seen that for the case of an anterior lesion, a markedly better performance on L1 syntactic tasks was observed in various studies. Considering language proficiency at the time of stroke, the language best recovered is the language most frequently used at the time of stroke and focussed on during speech therapy; in the example of the French-German bilingual, German was recovered better. This is closely tied to the patient's emotional involvement with the languages: it is integrative motivation (versus instrumental motivation) which seems to help language performance; motivation starts high and remains high. Unfortunately, language proficiency at the time of a stroke and emotional involvement cannot be easily measured. Common proficiency assessments in test situations address only skills such as listening, reading, speaking and writing but not, for example, the knowledge needed to respond to complex adjacency pairs in conversations. Emotional involvement is of course related to a person's affinity for a language or country, shared cultural values, stereotypes and history, experiences, modes of use (e.g., social engagement versus formal bureaucratic discourse) and styles. Finally, the relative distance between languages also has some relevance to recovery, although it must be said that background linguistic factors also have a significant effect (e.g., phonetic similarities, grammatical gender differences between the L1 and L2, and so on).

One may conclude that studies of highly measurable and quantifiable parameters, such as the age of acquisition and the place of lesion, have produced more results than comparatively imprecise ones on emotional involvement and language proficiency/competence at the time of a stroke. But it is exactly the latter parameters that most progress can and should be made on in the future.

I used to be a highly multilingual person at the time of my stroke, speaking and understanding five different modern languages (Swiss German, Standard German, French, English and Italian). Taking into account that I recovered my Swiss German proficiency but not my Standard German proficiency, Swiss German, a heteronomous variety of Standard German, would - in my case - appear to be a fully fledged language. However, a generalization of this relationship between Swiss and Standard Germans remains a controversial topic.

It is not easy to determine what has been going on in my "black box" of languages, but I tend to see language proficiency at the time of my stroke and emotional involvement as having the greatest cumulative effects on my recovery rates, with age of acquisition and relative distance between languages having fewer effects.

Most importantly, we can account for my marked recovery of Swiss German by appealing to my emotional involvement with the language, and for my marked recovery of English as being due to both my proficiency at the time of the stroke and my emotional involvement with the language.

The relative absence of recovery of French and the total absence of Italian can be explained by my marginal involvement with them at the time of the stroke, and possibly by the relative distance of these languages to my mother tongue. The relative absence of Standard German from my repertoire is best accounted for by lack of emotional involvement with the language - I learnt it purely for instrumental reasons and not for integrative ones. In addition, there may be also an antagonistic recovery pattern between good progress in Swiss German and English, and poor progress in Standard German, French and Italian.

It is hoped that with further therapy - although this becomes increasingly difficult and cumbersome as time goes by and progress slows - I can achieve something close to my multilingual proficiency before the stroke and will be able to speak and understand all the languages I so cherished.

\section{Acknowledgements}

Due to partial paralysis of my right arm, this text was dictated using a speech recognition program, Dragon Dictate for Mac OS X, and was then automatically typed into the file. I would like to thank Robinson College, Cambridge for their generous hospitality during the finalization of the paper. I would also like to thank the reviewers of the article as well as Jean Hannah, Peter Trudgill and my partner Gunter Siddiqi for their generous help and support in writing, correcting and publishing this paper.

\section{References}

Annoni, J.-M. (2011). Le cerveau bilingue en Neurologie [PowerPoint slides], CHUV Hospital Lausanne, 5 October 2011. 
Archibald, J. (1996). Second language acquisition. In W. O’Grady, M. Dobrovolsky, \& F. Katamba (Eds.), Contemporary Linguistics (3rd ed., pp. 503-539). London: Longman. http://dx.doi.org/10.1017/S0272263100014716

Bahtia, T. K., \& Ritchie, W. C. (Eds). (2004). The Handbook of Bilingualism. Oxford, UK: Blackwell Publishing.

Crowley, T., \& Bowern, C. (2009). An Introduction to Historical Linguistics. Oxford, UK: Oxford University Press.

Daneš, F. (1994). Involvement with language and in language. Journal of Pragmatics, 22(3-4), 251-264. http://dx.doi.org/10.1016/0378-2166(94)90111-2

Elder, C., \& Davies, A. (1998). Performance on ESL examinations: Is there a language distance effect? Language and Education, 12(1), 1-17. http://dx.doi.org/10.1080/09500789808666736

Finegan, E. (1989). Language: Its Structure and Use (2nd ed.). Fort Worth, TX, London: Harcourt Brace College Publishers.

Gitterman, M. R., Goral, M., \& Obler, L. K. (2012). Aspects of Multilingual Aphasia. Bristol, UK: Multilingual Matters.

Ijalba, E., Obler, L. K., \& Chengappa, S. (2004). Bilingual Aphasia. In T. K. Bahtia, \& W. C. Ritchie (Eds.), The Handbook of Bilingualism (pp.71-89). Oxford, UK: Blackwell Publishing.

Lass, R. (1987). The Shape of English: Structure and History. London: J. M. Dent \& Sons Ltd.

Mali, G., \& Goral, M. (2004). Nonparallel recovery in bilingual aphasia: Effects of language choice, language proficiency and treatment. International Journal of Bilingualism, 8(2), 191-219. http://dx.doi.org/10.1177/13670069040080020501

Meinzer, M., Obleser, J., Flaisch, T., Eulitz, C., \& Rockstroh, B. (2007). Recovery from aphasia as a function of language therapy in an early bilingual patient demonstrated by fMRI. Neuropsychologia, 45(6), 1247-1256. http://dx.doi.org/10.1016/j.neuropsychologia.2006.10.003

National Institute of Health. (2008). NIH Pub. No. 97-4257. Retrieved June 4, 2012, from http://www.nidcd.nih.gov/health/voice/pages/aphasia.aspx

Obler, L. K., \& Gjerlow, K. (1999). Language and the Brain. Cambridge Approaches to Linguistics. Cambridge, UK: Cambridge University Press. http://dx.doi.org/10.1006/brln.1999.2101

Renfrew, C., McMahon, A. M. S., \& Trask, R. L. (2000). Time Depth in Historical Linguistics. Cambridge, UK: McDonald Institute for Archaeological Research.

Rivers, W. P., \& Golonka, E. M. (2009). Third language acquisition theory and practice. In M. H. Long, \& C. J. Doughty (Eds.), The Handbook of Language Teaching (pp. 250-266). Oxford, UK: Blackwell Publishing. http://dx.doi.org/10.1002/9781444315783.ch15

Schwyter, J. R. (2011). "Me talk funny": A stroke patient's personal account. English Today, 27(4), 49-52. http://dx.doi.org/10.1017/S0266078411000538

Tschirren, M., Laganaro, M., Michel, P., Martory, M.-D., Di Pietro, M., Abutalebi, J., \& Annoni J.-M. (2011). Language and syntactic impairment following stroke in late bilingual aphasics. Brain \& Language, 119(3), 238-242. http://dx.doi.org/10.1016/j.bandl.2011.05.008

\section{Notes}

Note 1. I deliberately use the term multilingual here, although in some of the sociolinguistic literature speakers of more than two languages are nevertheless referred to as bilingual.

Note 2. Readers at the Oxford University Bodleian library have to take this oath, swearing not to damage books or kindle a flame in the library. 